\title{
Institutionalization of dairy innovation platforms: A study on Samagra project in Kerala
}

\author{
Ditty Maria Dominic and Jancy Gupta
}

Received: 16 April June 2019 / Accepted: 04 August 2019 / Published online: 28 October 2019

(c) Indian Dairy Association (India) 2019

\begin{abstract}
The present study assesses the extent of institutionalization of dairy based Samagra projects in Kerala as an Innovation Platform (IP). The study was conducted in purposively selected Thrissur and Palakkad districts of Kerala. From each district, 3 Panchayats were selected purposively and from each selected Panchayat 1 Self Help Group (SHG) with at least 20 members were selected. So a total of 6 SHGs were covered. From each SHG 20 members were selected based on the criteria of one year membership in the SHG, constituting a total sample size of 120 respondents. The data were collected using interview schedule. An institutionalization index was specially developed for the study with Structure, Conduct and Performance as the indicators. Out of the three indicators the structure of the innovation platform had highest scale value of 7.55 and highest index value of 0.27 . This indicates the significance of structure indicator over conduct and performance indicators in the institutionalization process. According to 45.83 percent of the respondents, institutionalization of Samagra as an Innovation Platform has taken place only in a medium level. A low level of institutionalization has taken place according to 27.50 percent of the respondents whereas 26.66 percent of the respondents agreed that the innovation platform is highly institutionalized. The field level problems in implementation of the project, medium linkages between actors and lack of capacity building and training were
\end{abstract}

Dairy Extension Division, National Dairy Research Institute, Karnal, Haryana

Ditty Maria Dominic $(\bowtie)$

Dairy Extension Division

National Dairy Research Institute, Karnal, 132001, Haryana, India

Email: ditty794@gmail.com; Mobile: +919991168361 some of the reasons for the medium level of institutionalization. Establishment of promotion councils, capacity building of the private sector actors is some of the suggestions which can contribute to more institutionalization of the project. The "Institutionalization Index" developed in this study would be useful in assessing the institutionalization of other innovation platforms in agriculture/ dairy sector.

Keywords: Conduct, Innovation platform, Institutionalization, Performance, Self-help group, Structure

\section{Introduction}

Innovation platforms (IP) are dynamic spaces which brings together multiple actors together to exchange knowledge and take synergic action to solve a common problem where in every member contributes something unique and makes it a win-win collaborative mechanism (Makini et al. 2013; Pali and Swaans, 2013). The striking characteristic feature of an IP is that, it operates in a value chain and innovation of different types can occur anywhere along the value chain (Metcalfe and Ramlogan, 2008). In communities with IPs innovative activity is more diverse. The Goat IPs in South Africa improved the market, productivity, policy as well as monitoring, impact evaluation and adaptation (Makini et al. 2016). The study on maize value chain of Burkina Faso reported that IP facilitates better organization of stakeholders in value chains and the adoption of technology with great potential to contribute to wealth creation (Maru, 2018). In Mozambique the IP at Changara is used by local government officials as one of the major entry points for government-led interventions in the livestock community (Filipe, 2010).

Innovation platforms are currently driven by projects or "external" agents, and therefore sustainability beyond the life of these projects is a key issue of concern (Anandajayasekaram, 2011). Thus, it is important to institutionalize the concept of IPs and move away from a fragmented 'piecework' approach. Institutionalization refers to the permanent integration or mainstreaming of processes and perspectives within multistakeholder contexts for the purpose of guiding their mandated activities (Anandajayasekeram et al. 2009). Very few studies have 
been carried out on measuring institutionalization. Multilevel platforms lacked effective coordination mechanisms and they functioned just as long as financially supported by donors (Moumouni and Labarthe, 2012). Institutionalization is not simply present or absent; it is a variable, with different degrees of institutionalization (Davies et al. 2018). Institutionalization results in acknowledgement and acceptance of the principles of IPs as its pillars (Nederlof, 2012; Pretty, 2010). The present study considers Samagra project in Kerala as an IP. It is implemented in all throughout Kerala state can be considered as an IP as it; envisages integrated approach covering the entire value chain, bringing in technical support of professional agencies and experts, and convergence of the three-tier PRIs. The ultimate beneficiaries of the Samagra project is SHG members of the Kudumbasree mission (It is a community organization of Self Help Groups of women in Kerala, framed and enforced by the State Poverty Eradication Mission of the Government of Kerala). The SHGs are accepted as relevant and powerful instrument of social, political and economic empowerment of women. (Antia and Kadekodi, 2002; Sinha and Sinha, 2002). The main aim of Samagra project is the development of agriculture and allied sectors in Kerala and thus the upliftment of lower sections of society. Thus, Samagra as an IP gives more emphasis on institutional innovation, which helps in unlocking the unlimited potential of individuals and organizations (Hagel and Brown, 2013). Samagra acts as an IP by bringing together multiple stakeholders aiming to improve the existing situation/conditions around a common interest/challenge faced by Kerala in agriculture and allied sector. The current paper will provide information on, to what extent Samagra as an IP is institutionalized and the factors affecting it.

\section{Methodology}

The study was conducted in Kerala state which was selected purposively keeping in view the success of Kudumbasree programme in boosting in the state in various sectors including dairy. The Samagra project which had two animal husbandry projects (cow rearing) namely Nature Fresh (NF) and Ksheerasagaram were selected. Two districts of Kerala namely Thrissur and Palakkad were purposively selected as these districts had highest number of dairy based Kudumbasree SHGs working under the Samagra project, about $97 \%$ of cattle population is cross breed in the Thrissur district which is very high compared to other districts ( NDDB, 2016 a), Palakkad district was the highest milk producer in the state.(644.12 lakh litres in 2012,CLPR) and high success rate of Ksheerasagaram project and Nature Fresh programme of Samagra was reported in these districts (Kudumbasree, 2010). Further, 3 Panchayats from each district with highest number of dairy based SHG under Samagra were selected purposively. From each Panchayat 1 dairy based Samagra SHGs was selected on the criteria that at least 20 members should be there. So a total of 6 SHGs were covered. From each SHG 20 members were selected based on the criteria of one year membership in the SHG. Therefore, a total of 120 respondents was selected.

Index was developed for measuring institutionalization of Samagra as an IP. Indicators were selected based on the conceptual framework put forward by Cadilhon et al. (2013). Structure, conduct and performance were the three indicators selected. Structure of the platform signified the individual SHGs structure as well as the structure of the platform itself. Elements of the conduct reflect how effectively the value chain actors carry out the activities like decision making, monitoring, follow up, marketing, communication between the different value chain actors in the IP. Performance is the indicator that describes what innovation platform is supposed to achieve to benefit its member. These indicators were ranked based on the perceived significance of a group of judges of various designations including Scientists, Assistant Professors, Ph.D Scholars, in determining the institutionalization of innovation platforms. The Frequencies of Ranks as given by 30 Judges, Proportions (p), C Values and Rc Values for three Indicators of Institutionalization Index by using Normalized Rank Order Method Suggested by Guilford (1954) as given in Table 1. By referring the available literature on relevant subject, a total 95 statements were collected covering the almost entire universe of content. The researchers, farmers and extension experts were also consulted for selecting indicators. The statements were edited as per 74 informal criteria suggested by Edwards (1957) as outcome 80 statements were eliminated. Finally, 15 statements were retained after editing and considered for judge's rating. The judges were asked to indicate degree of relevancy on each indicator with three point continuums 'Most Relevant, Relevant and Least Relevant' with scoring 3, 2, and 1, respectively. The Relevancy Weightage (RW) and Mean Relevancy Score (MRS) were worked out for all the selected indicators individually. Each indicator of Institutionalization Index consists of number of statement and hence, their range of total scores was different. Therefore, the total score of each dimension was converted into unit score by using simple range and variance and composite index was computed followed by standardization of the index for ascertaining its validity.

\section{Results and Discussion}

The level of institutionalization is measured based on the responses of the SHG members who are the major stakeholders of the IP. Institutionalization score for the structure indicator was the highest 0.27 (Table 2) among the three indicators which implied that the structure component of the innovation platform contributes mainly to its institutionalization. The membership criteria and composition, regulatory framework and bylaws present, agreed goals and responsibilities by the multi stakeholders, source of funding and incentives given constituted the structure component. Majority of the members were homogenous with respect to socio economic characteristics like age, sex, education, income which promoted more consensus 
among them in deciding the goals and carrying out the activities. Well laid out regulatory framework by the Samagra IP for bringing together the various stakeholders in the value chain and guiding the value chain activities with provision of loans and incentives to the SHG members are some of the crucial factors that contributed to the medium level of institutionalization of Samagra IP. Institutionalization score for conduct was 0.23 (Table 2). This indicates that, after structure, the conduct component contributes to the institutionalization. More access to information sources and availability of timely information through linkage with other stakeholders (Sparrow et al. 2018) or through regular attendance in meetings and trainings updates the stakeholders about various innovations or activities related to technology, marketing and credit in the value chain strengthened the institutionalization process. Performance was measured according to indicators that are relevant to the objectives set out by the stakeholders at its inception like stable income generation, regular accessible market as well as the overall objective of the IP i.e, to increase the milk production of the state and attaining self sufficiency along with providing livelihood support through dairying to the rural women. The institutionalization score for performance component was the lowest, 0.17 (Table 2). Thus, the Structure of the IP was the major indicator of institutionalization followed by its conduct and performance.

According to majority (45.83\%) of the respondents, institutionalization of Samagra as an Innovation Platform has taken place only in a medium level (Table 3). A low level of institutionalization has taken place according to 27.50 percent of the respondents whereas 26.66 percent of the respondents agree that the innovation platform is highly institutionalized. Although the project guidelines layout a good framework for monitoring and evaluation in the form of monitoring team (Jeeva), at the field level they didn't carry out their monitoring and evaluation activities on a regular basis. The main reason was that the monitoring team (Jeeva) members were given only Rs.200 per day which do not meet the field visit expenses. Thus, monitoring whether their activities were based on Samagra guidelines were not done. So problems like non repayment of loans by some members, usage of funds given for dairying activities for other purposes, not meeting the standards stated in the guidelines in milk production and maintenance activities were not brought under the notice of higher authorities for taking corrective measures. The group marketing activity carried out by the SHG under NF model is an effective innovative approach adopted by the IP members which helps in reducing the length of the dairy value chain, increasing the milk quality and fetching remunerative prices for the milk with a hike in its demand. Out of the 6 SHGs studied, only 3 were carrying out group marketing. Thus, the group marketing should be facilitated and promoted in every SHG. A brand value can be created if more groups are engaged in selling milk collectively, which in turn will aid in institutionalizing the IP. The processing and value addition of the milk is a completely unexploited area, although there is a huge opportunity. From the survey it was found that the SHG members are interested in establishing processing unit, so promotion of processing and

Table 1 Selection of indicators for institutionalization index

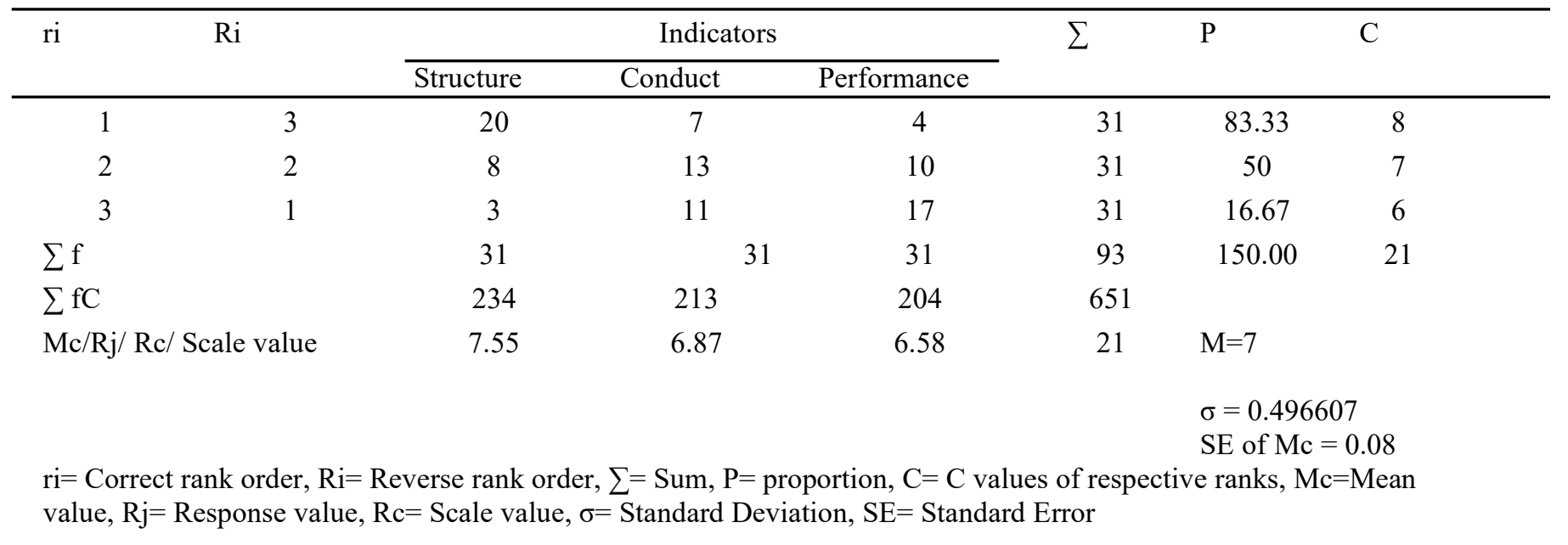

Table 2 Distribution of respondents as per scores obtained on the indicators of institutionalization index

\begin{tabular}{llc}
\hline S.No. & Indicators & Score \\
\hline 1 & Structure & 0.27 \\
2 & Conduct & 0.23 \\
3 & Performance & 0.17 \\
\hline
\end{tabular}

Table 3 Distribution of respondents on the continuum of institutionalization index to assess the level of institutionalization of the Innovation Platform

\begin{tabular}{llc}
\hline Category & Class interval & Percentage \\
\hline Low & $0.39-0.57$ & 26.67 \\
Medium & $0.58-0.68$ & 43.33 \\
High & $0.69-0.82$ & 30.00 \\
\hline
\end{tabular}


Table 4 The selected statements of the respective indicators of Institutionalization index with their Relevancy weightage and Mean Relevancy Score

\begin{tabular}{|c|c|c|c|}
\hline Sl.No & Structure & $\begin{array}{l}\text { Relevancy } \\
\text { weightage }\end{array}$ & $\begin{array}{l}\text { Mean } \\
\text { Relevancy } \\
\text { Score }\end{array}$ \\
\hline 1 & $\begin{array}{l}\text { The homogeneity of the SHG members with respect to various socio } \\
\text { economic featurescontribute to institutionalization }\end{array}$ & 0.89 & 2.68 \\
\hline 2 & $\begin{array}{l}\text { A well organized structure for decision making, monitoring and } \\
\text { evaluationassists in institutionalization }\end{array}$ & 0.90 & 2.71 \\
\hline 4 & $\begin{array}{l}\text { Formation of a separate committee for marketing and promoting linkages } 0.92 \\
\text { with other stakeholders will lead to institutionalization }\end{array}$ & 2.76 & \\
\hline 5 & $\begin{array}{l}\text { Adequate and consistent financial support by the funding organization can } \\
\text { aid in institutionalization } \\
\text { Conduct }\end{array}$ & 0.93 & 2.81 \\
\hline 7 & $\begin{array}{l}\text { Regular monitoring and supervision of the activities of the SHG members, } \\
\text { by the implementing agency will aid in institutionalization }\end{array}$ & 0.92 & 2.77 \\
\hline 8 & $\begin{array}{l}\text { Access to to adequate and timely updated information from various } \\
\text { stakeholders will assist in institutionalization }\end{array}$ & 0.85 & 2.55 \\
\hline 9 & $\begin{array}{l}\text { Existence of a quorum for meeting and training which conducts meetings } \\
\text { and trainings at regular time intervals can enhance institutionalization }\end{array}$ & 0.86 & 2.60 \\
\hline 10 & $\begin{array}{l}\text { Specified rules and guidelines for implementation, control and direction of } \\
\text { activities carried out in the value chain will help in institutionalization } \\
\text { Performance }\end{array}$ & 0.87 & 2.61 \\
\hline 11 & $\begin{array}{l}\text { Increased milk production and attainment of remunerative price for milk/ } \\
\text { milk products enhances institutionalization }\end{array}$ & 0.87 & 2.61 \\
\hline 14 & Supply of quality product to the consumers promotes institutionalization & 0.85 & 2.55 \\
\hline 15 & Widening the scope of activities into processing and value addition $\quad 0.85$ & 2.55 & \\
\hline
\end{tabular}

value addition should be more emphasized by the Samagra officials. With appropriate market support strategies the members could effectively build enterprises as a source of their employment and income. IPs can create new institutional conditions that allow smallholders to capture opportunity (Hounkonnou et al. 2018). The mandated activities like building biogas plants attached to the cattle sheds and group fodder cultivation is not done by majority of the farmers. Low landholding size, the lack of awareness about the advantages of biogas plants, lack of support from the agriculture department in installation of biogas plants and growing fodder were the major constraints that refrained the farmers from carrying out these mandated activities which have affected the institutionalization process adversely. Well established linkages between the various actors of the IP value chain promotes more innovative activities and helps in sustaining the IP (Schut et al. 2019), which inturn promotes institutionalization of the IP. Conducting trainings, exhibitions, workshops in collaboration with Samagra SHGs in other districts will give more exposure to the SHG members. All the SHG members indicated that the Samagra has helped them tide over the difficulties they had experienced by providing an alternate income source to them. Linkages with public sector and private sector institutions and NGOs can be facilitated and strengthened by setting up a promotion council this will also help in carrying out capacity development activities like trainings, field visits, workshops, multistakeholder meetings etc. the Thus emphasizing 
and working on the above suggestions can enhance the level of institutionalization.

\section{Conclusions}

Medium level of institutionalization of Samagra project as an innovation platform are mainly due to the weak implementation and follow up of the project by the officials, practical field level problems like low land availability for group fodder cultivation, conflicts between the members, less interest of the marketing agents in carrying out the activities and weak linkages with public and private sector actors. To promote institutionalization, the public sector could further support interactions, collective actions, and broader public private partnership programs. The public sector might be better suited to a bridging or facilitative role between smallholders and other actors.As the per capita landholding size is small collective fodder cultivation should be facilitated. For this the Samagra officials must find a way to make availability of land on lease to farmers. The processing and value addition of the milk is a completely unexploited area, although there is a huge opportunity. Only by Institutionalizing the IP its benefits can be penetrated to the lower sections of the society in a broad manner. Thus, more steps and modifications should be taken up to institutionalize the IP.

\section{Acknowledgements}

The author duly acknowledges the Director, ICAR-National Dairy Research Institute, Karnal, Haryana (India) for providing all the necessary facilities for carrying out the present work.

\section{References}

Anandajayasekeram P, Puskur R, Zrfu E (2009) Applying innovation system concepts in agricultural research development. A learning module. International Livestock Research Institute (ILRI), Nairobi, Kenya.

Anandajayasekeram P (2011) The role of agricultural R\&D within the agricultural innovation systems framework. InReport Prepared for the ASTI/IFPRI-FARA Conference

Antia NH, Kadekodi GK (2002) Dynamics of rural development: Lessons from Ralegan Siddhi. Foundation for Research in Community Health, Pune

Cadilhon J (2013) A conceptual framework to evaluate the impact of innovation platforms on agri-food value chains development. Paper prepared In Seminar on Pro-poor Innovations in Food Supply Chains, Ghent, Belgium

Davies J, Maru Y, Hall A, Abdourhamane IK, Adegbidi A, Carberry P, Dorai K, Ennin SA, Etwire PM, McMillan L, Njoya A(2018) Understanding innovation platform effectiveness through experiences from west and central Africa. Agric Syst 1: 321-34

Edwards AL (1957) Social desirability and probability of endorsement of items in the interpersonal check list. J Abnormal Social Psychol 55: 394

Hagel J, Brown JS (2013) Institutional innovation: Creating smarter organizations to scale learning. Deloitte Center for the Edge 12: 122

Hounkonnou D, Brouwers J, Van Huis A, Jiggins J, Kossou D, Röling N, Sakyi-Dawson O, Traoré M (2018) Triggering regime change: a comparative analysis of the performance of innovation platforms that attempted to change the institutional context for nine agricultural domains in West Africa. Agric Syst 1: 296-309.

Makini FW, Kamau GM, Makelo MN, Adekunle W, Mburathi GK, Misiko M, Pali P, Dixon J (2013) Operational field guide for developing and managing local agricultural innovation platforms. Nairobi. Kenya. KARI. P. 92.

Makini FW, Kamau G, Makelo M, Mose LO, Salasya B, Mulinge W, Ong'ala J (2016) Status of Agricultural Innovations, Innovation Platforms, and Innovations Investment. 2015 PARI project country report: Republic of Kenya.

Metcalfe S, Ramlogan R (2008) Innovation systems and the competitive process in developing economies. Q Rev Econ Finance 48: 433-46

Moumouni I, Labarthe P (2012) Institutionalization of knowledge sharing platforms in the last three decades in Francophone Sub Saharan Africa. In Proceedings of the 10th European IFSA symposium

NDDB (2016) Dairying in Kerala: A statistical profile

Nederlof S, Pyburn R (2012) One finger cannot lift a rock: facilitating innovation platforms to trigger institutional change in West Africa.

Pali PN, Swaans K (2013) Guidelines for innovation platforms: Facilitation, monitoring and evaluation.

Pretty J, Toulmin C, Williams S (2011) Sustainable intensification in African agriculture. Int J Agric Sustainability 9: 5-24

Schut M, Kamanda J, Gramzow A, Dubois T, Stoian D, Andersson JA, Dror I, Sartas M, Mur R, Kassam S, Brouwer H (2019) Innovation platforms in agricultural research for development: Ex-ante appraisal of the purposes and conditions under which innovation platforms can contribute to agricultural development outcomes. Exp Agric 55: 575-96

Sinha S, Sinha F (2002) Sustainability and development: evaluating the performance of Indian microfinance. Beyond Microcredit: Putting Development Back into Microfinance 263-299

Sparrow AD, Traoré A (2018) Limits to the applicability of the innovation platform approach for agricultural development in West Africa: Socio-economic factors constrain stakeholder engagement and confidence. Agric Syst 165: 335-343

Maru Y, Sparrow A, Stirzaker R, Davies J (2018) Integrated agricultural research for development (IAR4D) from a theory of change perspective. Agric Syst 165: 310-20 